\title{
TCEB3C a putative tumor suppressor gene of small intestinal neuroendocrine tumors
}

\author{
Katarina Edfeldt', Tanveer Ahmad', Göran Åkerström', Eva Tiensuu Janson ${ }^{2}$, \\ Per Hellman', Peter Stålberg', Peyman Björklund' and Gunnar Westin' \\ Departments of ${ }^{1}$ Surgical Sciences ${ }^{2}$ Medical Sciences, Uppsala University Hospital, Uppsala University, \\ Entrance 70, 3 tr, SE-75185 Uppsala, Sweden
}

Correspondence should be addressed to $\mathrm{G}$ Westin Email gunnar.westin@surgsci.uu.se

\begin{abstract}
Small intestinal neuroendocrine tumors (SI-NETs), formerly known as midgut carcinoids, are rare and slow-growing neoplasms. Frequent loss of one copy of chromosome 18 in primary tumors and metastases has been observed. The aim of the study was to investigate a possible role of TCEB3C (Elongin A3), currently the only imprinted gene on chromosome 18, as a tumor suppressor gene in SI-NETs, and whether its expression is epigenetically regulated. Primary tumors, metastases, the human SI-NET cell line CNDT2.5, and two other cell lines were included. Immunohistochemistry, gene copy number determination by PCR, colony formation assay, western blotting, real-time quantitative RT-PCR, RNA interference, and quantitative $\mathrm{CpG}$ methylation analysis by pyrosequencing were performed. A large majority of tumors (33/43) showed very low to undetectable Elongin A3 expression and as expected $89 \%$ (40/45) displayed one gene copy of TCEB3C. The DNA hypomethylating agent 5-aza-2'-deoxycytidine induced TCEB3C expression in CNDT2.5 cells, in primary SI-NET cells prepared directly after surgery, but not in two other cell lines. Also siRNA to DNMT1 and treatment with the general histone methyltransferase inhibitor 3-deazaneplanocin $A$ induced TCEB3C expression in a cell type-specific way. CpG methylation at the TCEB3C promoter was observed in all analyzed tissues and thus not related to expression. Overexpression of TCEB3C resulted in a $50 \%$ decrease in clonogenic survival of CNDT2.5 cells, but not of control cells. The results support a putative role of TCEB3C as a tumor suppressor gene in SI-NETs. Epigenetic repression of TCEB3C seems to be tumor cell type-specific and involves both DNA and histone methylation.
\end{abstract}

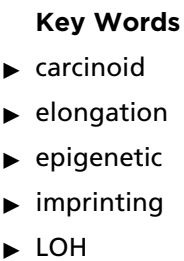

Endocrine-Related Cancer (2014) 21, 275-284

\section{Introduction}

Small intestinal neuroendocrine tumors (SI-NETs) arise from the enterochromaffin cells which are scattered in the intestinal mucosa. The annual incidence of SI-NETs is about one case per 100000 , but the incidence and prevalence rates are increasing. The tumors are small (often $<2 \mathrm{~cm}$ ) and slow growing (Ki67 proliferation index is often $<2 \%$ ), but still have a lethal outcome with a 5-year survival rate around 65\% (Yao et al. 2008, Norlen et al. 2012). Many patients have tumor spread to regional lymph nodes and liver at the time of diagnosis. The tumors can produce hormones, e.g. serotonin and tachykinins, which can give rise to the carcinoid syndrome causing flushing, bronchoconstriction, and heart disease (de Herder 2007, Stålberg et al. 2009).

Published by Bioscientifica Ltd. 
NETs from the gastrointestinal tract (GEP-NET; gastroenteropancreatic NET) were previously divided according to their embryologic origin into foregut, midgut, and hindgut carcinoid tumors. GEP-NET usually develops in the small intestine, especially in the distal ileum. According to the WHO classification system, from year 2010, SI-NETs are divided into three grades (Bosman et al. 2010); Grade 1 Neuroendocrine neoplasm (Ki67 <3\%), Grade 2 Neuroendocrine neoplasm (Ki67 3-20\%), and Grade 3 Neuroendocrine carcinoma (NEC; Ki67 > 20\%).

The knowledge about genetic and epigenetic aberrations in SI-NETs is sparse. The most common aberration is loss on chromosome 18, which have been seen in 43-100\% (Kytola et al. 2001, Löllgen et al. 2001, Tonnies et al. 2001, Stancu et al. 2003, Wang et al. 2005, Kim do et al. 2008, Kulke et al. 2008, Andersson et al. 2009, Cunningham et al. 2011, Walsh et al. 2011), supporting the presence of a crucial tumor suppressor gene. Mutational analyses of several putative tumor suppressor genes located at 18q21-18q22 revealed no alterations (Löllgen et al. 2001, Kulke et al. 2008, Cunningham et al. 2011). Massively parallel exome sequencing of 48 SI-NETs has revealed a low general mutation rate and no recurrently mutated genes. Amplification of genes AKT1 or $A K T 2$ was observed in tumors from 16 patients (Banck et al. 2013). Recent analysis of a different tumor cohort by exome- and whole-genome sequencing (Francis et al. 2013) identified frameshift mutations (7.8\%) and hemizygous deletions $(14 \%)$ in CDKN1B on chromosome 12p13.1-p12, which encodes the cyclin-dependent kinase inhibitor p27 (Kip1). Imprinted genes are of particular interest in cancer since only one mutational hit is required to fulfill the Knudson's two-hit hypothesis of tumor suppressor genes. Imprinted genes are epigenetically regulated and have a parental origin-specific differential expression of the two alleles and the epigenetic regulation is often tissue-specific (Ferguson-Smith 2011, Uribe-Lewis et al. 2011). Presently, the only known imprinted gene on chromosome 18 (http://www.geneimprint.com) is TCEB3C (18q21.1), which is maternally imprinted in some tissues (Strichman-Almashanu et al. 2002, Li et al. 2010) and encompasses a CpG island. Methylation of CpG islands in gene promoter regions often results in repressed gene expression (Jones 2012). The ubiquitously expressed TCEB3C encodes for Elongin A3, a polypeptide of 546 amino acids which is 49 and $81 \%$ identical to Elongin $\mathrm{A}$ and Elongin A2, respectively. Not much is known regarding Elongin A3 function, although it can like Elongin A form a stable complex with Elongin BC and stimulate the rate of transcription elongation by RNA polymerase II in vitro. Like Elongin A, Elongin A3 may be involved in ubiquitin-dependent degradation of proteins (Yamazaki et al. 2002).

This study investigated whether TCEB3C may present a tumor suppressor gene in small intestinal neuroendocrine cells and whether its expression may be regulated by epigenetic mechanisms.

\section{Materials and methods}

\section{Tissue specimens}

All 42 patients included in the study were diagnosed with SI-NETs and operated upon at Uppsala University Hospital between years 1995 and 2012. Informed consent was obtained from all patients and the study was approved by the local ethical committee, Uppsala. Twenty-nine patients were classified as NET-G1 and 13 as NET-G2. In total 64 tumors were analyzed: 27 primary tumors, 23 lymph node metastases, and 14 liver metastases. Only nine patients had succumbed making survival analysis inconclusive. Primary tumors and metastases were snap-frozen in liquid nitrogen and kept at $-70^{\circ} \mathrm{C}$. A human SI-NET cell line, CNDT2.5, developed from a liver metastasis from a patient diagnosed with primary ileal SI-NET (Van Buren et al. 2007), was used in the experiments reported here at cell passages 10-30. These cells expressed neuroendocrine markers and somatostatin receptor 2 and responded to synthetic somatostatin analog (octreotide) treatment (Van Buren et al. 2007, Li et al. 2012), although skepticism regarding the neuroendocrine authenticity of this cell line has also been raised (Ellis et al. 2010). The growth medium for CNDT2.5 was DMEM-F12 complemented with 10\% fetal bovine serum (Sigma Aldrich), 1\% vitamins, $1 \%$ L-glutamine, $1 \%$ sodium pyruvate, $1 \%$ nonessential amino acids and $1 \%$ penicillin-streptomycin (PEST), and the cells were cultured at $37{ }^{\circ} \mathrm{C}$ in $5 \% \mathrm{CO}_{2}$. Two other cell lines were used for comparisons. The human parathyroid tumor cell line sHPT-1 was used at cell passages 18-30 and the cells were routinely tested for parathyroid hormone expression by immunostaining of cultured fixed cells (Björklund et al. 2007). The human embryonic kidney cell line HEK293T was obtained from ATCC (LGC, Promochem, Sweden) and used at cell passages 10-30. For extraction and purifying of RNA and DNA the AllPrep DNA/RNA kit (Qiagen) was used according to manufacturer's instructions. DNA, RNA and protein quantities were determined by NanoDrop measurements.

Published by Bioscientifica Ltd. 


\section{Immunohistochemistry}

Paraffin embedded tumor tissue sections ( $5 \mu \mathrm{m})$ were passed through descending alcohol concentrations and distilled water. Background staining was blocked with 3\% hydrogen peroxide and heated in citrate buffer. The tissues were treated with normal goat serum and a rabbit polyclonal antiTCEB3C antibody (ab69873; Abcam, Cambridge, UK). A biotinylated secondary antibody was added to the tissues and then treated with ABC complex. Visualization was done with DAB color reagent. A peptide rabbit polyclonal antiElongin A3 antibody was also used (Santa Cruz, sc-84811) and specificity of the antibody was verified using a blocking peptide (sc-84811P). Fourty-three different tumors were evaluated: 24 primary tumors, 14 lymph node metastases, five liver metastases, and also normal kidney tissue. Consecutive tissue sections of intestinal mucosa were stained with the anti-TCEB3C antibody (Abcam, ab69873) or a mouse monoclonal anti-chromogranin A antibody (Ab-1, LK2H10; Thermo Fisher Scientific, Pittsburgh, PA, USA).

\section{Drug treatment and transfection}

CNDT2.5 $\left(2 \times 10^{5}\right)$, HEK293T $\left(8 \times 10^{5}\right)$, and sHPT-1 $\left(2 \times 10^{5}\right)$ cells were distributed onto six-well plates and treated with 5-aza-2'-deoxycytidine (5-aza-dC), a global hypomethylating agent, or 3-deazaneplanocin A (DZNep), a global histone methylation inhibitor (Miranda et al. 2009). $1.0 \mu \mathrm{M}$ 5 -aza-dC or $5.0 \mu \mathrm{M}$ DZNep were used and treatments continued for $72 \mathrm{~h}$. Growth medium with additions were changed every $24 \mathrm{~h}$. To further analyze DNA methylation, CNDT2.5 cells $\left(2 \times 10^{5}\right)$ were transfected with siRNA to DNA methyltransferase 1 (DNMT1) (sc-156049; Santa Cruz) and control nonsilencing siRNA (Qiagen). After $24 \mathrm{~h}$, the cells were transfected again and harvested after $72 \mathrm{~h}$ of transfection for DNA, RNA, and protein preparations. The transfection reagent INTERFERin (Polyplus transfection) was used with 20 pmol siRNA. Triplicate samples were analyzed and the experiments were repeated twice.

The cells from 11 SI-NETs were prepared directly after surgery according to a procedure described previously (Liu et al. 2001). Ten liver metastases and one lymph node metastasis were cultured and treated with $0.1 \mu \mathrm{M} 5$-aza-dC. Treatment continued for $72 \mathrm{~h}$ and fresh 5 -aza-dC was added every $24 \mathrm{~h}$. RNA was extracted from treated and control cells.

\section{Western blotting analysis}

Western blotting analysis were done on protein extracts prepared in Cytobuster Protein Extract Reagent
(Merck Millipore) with Complete protease inhibitor cocktail (Roche Diagnostics $\mathrm{GmbH}$ ). Primary rabbit polyclonal anti-DNMT1 (ab16632), rabbit polyclonal antiTCEB3C (sc-84811), and goat polyclonal anti-actin (sc-1616) antibodies were used. Mouse monoclonal anti-DDK (TA50011, Origene, Rockville, MD, USA) antibody was used to detect Elongin A3 expression after transient transfection of the TCEB3C expression vector. After incubation with the appropriate secondary antibodies, bands were visualized using the enhanced chemiluminescence system (GE Healthcare, Piscataway, NJ, USA).

\section{Quantitative real-time RT-PCR}

Quantitative real-time RT-PCR (qRT-PCR) was performed after RT of DNA-free RNA with random hexamer primers using the 'First strand cDNA Synthesis kit', according to manufacturer's instructions (Thermo Fisher Scientific). Successful DNase I treatment of all RNA preparations was established by PCR analysis. qRT-PCRs were performed on the Step 1 qRT-PCR system (Applied Biosystems) using TaqMan Gene Expression Master Mix and assays for GAPDH (Hs02758991_g1) and TCEB3C (Hs01015402_s1). All samples were amplified in triplicates, and non-template controls were included. Each sample's mean threshold value was corrected for the corresponding mean value for GAPDH mRNA, used as internal control.

\section{Analysis of gene copy number}

Analysis of gene copy number was performed on DNA from the cell lines, normal kidney and 45 tumors; 19 primary tumors, 15 lymph node metastases, and 11 liver metastases. A duplex quantitative real-time PCR was performed with a FAM dye-labeled probe for TCEB3C and with a VIC dyelabeled probe for reference gene detection. Two different assays were used for TCEB3C; CCFARJL and CCD1TDD (Applied Biosystems). RNaseP (Applied Biosystems) was used as reference gene for all samples and for a limited number of tumors, the TERT gene (Applied Biosystems) was used with similar results. PCR conditions were as followed: $95^{\circ} \mathrm{C}$ for $10 \mathrm{~min}$, followed by 40 cycles of $95^{\circ} \mathrm{C}$ for $15 \mathrm{~s}$ and $60^{\circ} \mathrm{C}$ for 60 s. Four replicates of each sample were analyzed using 20 ng DNA per well. DNA from placenta and blood from a healthy donor was used as calibrators. Two tumors with known copy numbers from a previous LOH analysis (Löllgen et al. 2001) were included as controls of the quantitative PCR assay and showed the expected results. The data analysis was performed in CopyCaller software (Applied Biosystems).

Published by Bioscientifica Ltd. 


\section{Pyrosequencing}

Promoter methylation status was investigated for seven CpG sites in seven primary tumors and seven lymph node metastases (seven matched pairs), CNDT2.5, sHPT-1, HEK293T, and normal kidney. DNA was treated with bisulfite using EZ DNA methylation Gold Kit (Zymo Research, Irvine, CA, USA) and PCR amplified using HotStarTaq Plus Master Mix kit (Qiagen): 10 pmol of each primer and $2 \mu \mathrm{l}$ DNA was used as template. PCR was performed with an initial denaturation at $95^{\circ} \mathrm{C}$ for $15 \mathrm{~min}$, followed by 45 cycles of $94^{\circ} \mathrm{C}$ for $15 \mathrm{~s}, 51^{\circ} \mathrm{C}$ for $20 \mathrm{~s}, 72^{\circ}$ for $20 \mathrm{~s}$, and completed with $72^{\circ} \mathrm{C}$ for $7 \mathrm{~min}$. Forward primer used was: 5'-GTTAAAGGTAGAATTTAGTGGGGTGTG-3', and reverse primer: $5^{\prime}$-CCCCCTAAACCCCTAAACTACC-3'. Sequencing primer: 5'-GGGGTATAGTAGTTTATTTG. Sequence analyzed: 5'-GYGTGGATYGTTTYGATTGGTTGYGTTGGGTTGAYGGAATGAATTTTTATYGGGGYGG-3'. The pyrosequencing was carried out with PyroMark Q24 (Qiagen), according to manufacturer's instructions, and $20 \mu$ PCR-product was used.

\section{Colony forming assay}

CNDT2.5 cells $\left(1 \times 10^{5}\right)$ were seeded onto six-well plates and transfected in triplicates with $4 \mu \mathrm{g}$ TCEB3C plasmid expression vector (Origene) or empty vector (pcDNA3.1) using $8 \mu$ l Lipofectamine 2000 transfection reagent (Life Technologies), according to manufacturer's instructions. Six hours after transfection, a fresh medium was added complemented with $1 \%$ PEST and $0.2 \mathrm{mg} / \mathrm{ml}$ geneticin (G418, Sigma Aldrich). After 24 h, 2000 cells were distributed onto six-well plates, a fresh medium with $0.2 \mathrm{mg} / \mathrm{ml}$ geneticin was added every $72 \mathrm{~h}$. After 8 days in G418 selection, the cells were fixed with $10 \%$ acetic acid/10\% methanol and stained with $0.4 \%$ crystal violet, and the visible colonies were counted. Successful transfections were monitored by RT-PCR for CNDT2.5 and SHPT-1 and by western blotting analysis for HEK293T, after $24 \mathrm{~h}$. sHPT-1 $\left(2 \times 10^{5}\right)$ and HEK293T $\left(1.5 \times 10^{6}\right)$ cells were transfected with the FuGENE 6 transfection reagent (Roche Diagnostics). Twenty four hours after transfection, 1000 sHPT-1 cells and 8000 HEK293T cells were distributed onto six-well plates in triplicates and after additional $24 \mathrm{~h}$ a fresh medium with $0.1 \mathrm{mg} / \mathrm{ml}$ geneticin was added. A fresh medium with antibiotics were added every $96 \mathrm{~h}$ and after 8 days in selection, the cells were fixed, stained, and counted as described above.

\section{Statistical analysis}

All data are presented as mean \pm s.D. and unpaired $t$-test was used for statistical analysis. $P<0.05$ was considered significant.

\section{Results}

One TCEB3C gene copy and undetectable expression of Elongin A3 for the majority of investigated SI-NETs

TCEB3C is considered an ubiquitously expressed gene and Elongin A3 was clearly immunohistochemically stained in chromogranin A-positive cells of the small intestine using a rabbit polyclonal anti-TCEB3C antibody (Fig. 1A). Elongin A3 expression was further analyzed in 43 SI-NETs (Supplementary Table 1, see section on supplementary data given at the end of this article) from 29 patients, 24 primary tumors, 14 lymph node metastases, and five liver metastases (Fig. 1B, C, and D). In 12 tumors more than $90 \%$ of the cells stained negatively for Elongin A3, in 21 tumors more than $50 \%$ of the cells were negative, and in ten tumors more than $50 \%$ of the cells showed positive Elongin A3 immunostaining. One patient presented positive staining in the primary tumor, but mostly negative staining in the lymph node metastasis, and another patient had mostly negative tumor cells in the primary tumor and lymph node metastasis, but mostly positive staining in the liver metastasis. There was no difference in staining patterns between Grade $1 \quad(n=28)$ and Grade $2(n=15)$ tumors. Thirty-two tumors displayed an insular growth pattern in the whole or in some part of the tissue section. For some of these $(n=14)$, the majority of insular cells was negative but showed a strong positive staining in the cells surrounding the islets (Fig. 1D). To control for specificity, a peptide rabbit anti-TCEB3C antibody was used and the staining was successfully blocked by the immunizing peptide (Fig. 1E).

Chromosome 18 aberrations are very common (43-100\%) in primary and metastatic SI-NETs, the majority of which have lost the entire chromosome (Kytola et al. 2001, Löllgen et al. 2001, Tonnies et al. 2001, Stancu et al. 2003, Wang et al. 2005, Kim do et al. 2008, Kulke et al. 2008, Andersson et al. 2009, Cunningham et al. 2011, Walsh et al. 2011). This was confirmed in the present cohort by determining the gene copy number of TCEB3C by quantitative PCR, using two different PCR assays (Supplementary Table 1). One gene copy of TCEB3C was detected in 40/45 (89\%) of the investigated tumor samples (from 36 patients).

Published by Bioscientifica Ltd. 
A

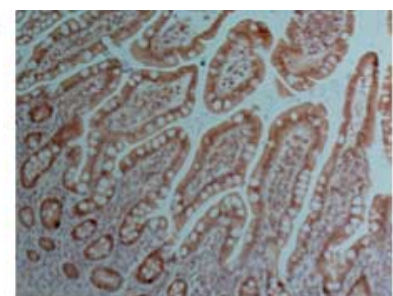

B

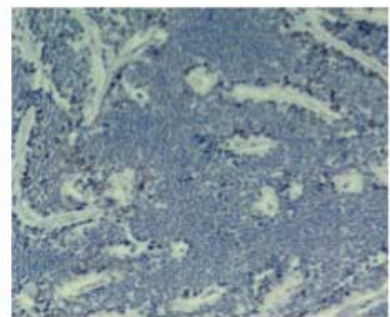

E

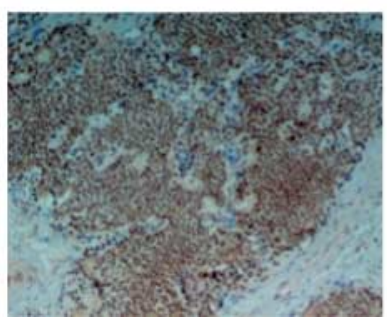

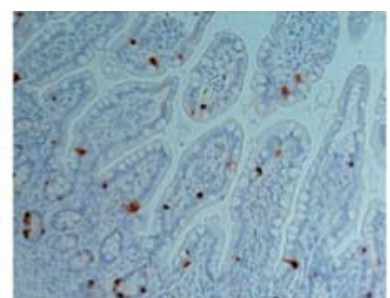

C
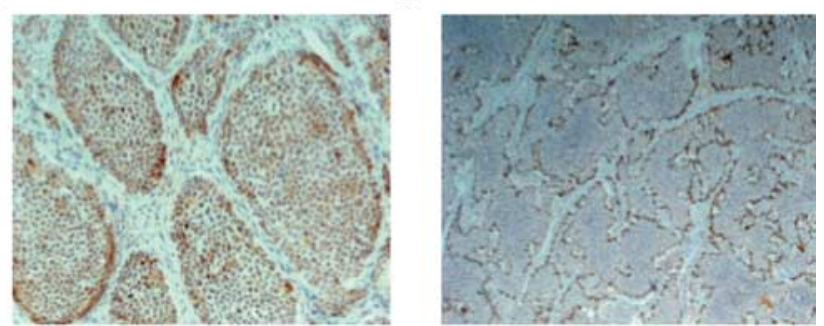

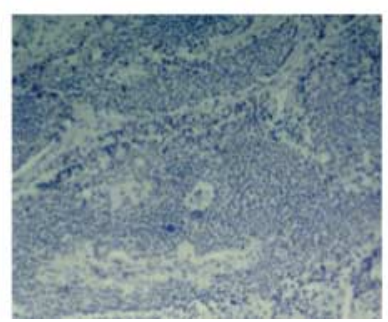

\section{Figure 1}

Expression of Elongin $\mathrm{A} 3$ as revealed by immunohistochemistry. Representative immunostainings of normal intestinal mucosa and lymph node metastases are shown using an anti-TCEB3C rabbit polyclonal antibody (A, B, C, and D). No staining was seen in the absence of primary antibody (data not shown). (A) Consecutive tissue sections of intestinal mucosa stained for Elongin A3 (left panel) and chromogranin

These included 19 primary tumors, 15 lymph node metastases, and 11 liver metastases. One primary tumor, one lymph node metastasis, and three liver metastases displayed two gene copies. Twenty-six of the tumors with one detected TCEB3C gene copy were included in the immunostaining analysis and in 13 of these the majority of tumor cells were negative, seven additional samples were completely negative ( $>90 \%$ ), and six displayed mostly positive staining for Elongin A3. One primary tumor with two gene copies displayed negative staining, a lymph node metastasis and a liver metastasis displayed two gene copies and in these two tumors the majority of cells were negative but displayed positive areas.

\section{The TCEB3C gene is epigenetically repressed in SI-NETs}

TCEB3C is known to be imprinted in some tissues (Strichman-Almashanu et al. 2002, Li et al. 2010), suggesting a possibility of one allele being epigenetically repressed also
(A) (right panel). (B) Negative staining. (C) Positive staining, insular growth pattern. (D) A tumor with insular growth pattern showing mostly negative staining and positive staining of cells surrounding the islets. (E) A tumor with insular growth pattern was positively stained for Elongin A3 (left panel) and successfully blocked with an excess of immunizing peptide (right panel).

in SI-NET cells. In order to investigate this possibility, the human SI-NET cell line CNDT2.5, harboring one TCEB3C gene copy, was treated with the DNA hypomethylating agent 5-aza-dC. The treatment strongly induced TCEB3C mRNA expression (90-fold) as well as increased Elongin A3 expression from a very low level in CNDT2.5 cells (Fig. 2A and $\mathrm{B})$. A role of DNA methylation was further supported by RNA interference experiments, by knocking down DNMT1. Transient transfection of siRNA to DNMT1 (Fig. 2C), but not of control siRNA, induced both TCEB3C mRNA (4.5-fold) and protein expression (Fig. 2D and E). In order to rule out a cell line-specific effect, metastatic SI-NET cells from 11 patients were freshly prepared directly after surgery and cultured in vitro in the presence of 5-aza-dC. The tumor cells had either one or two copies of the TCEB3C gene. Expression of the TCEB3C gene was significantly induced in ten out of the 11 cultures (two- to 16-fold) in the presence of 5-aza-dC (Fig. 2F), strongly supporting an epigenetic repressive mechanism in SI-NET cells. 
A

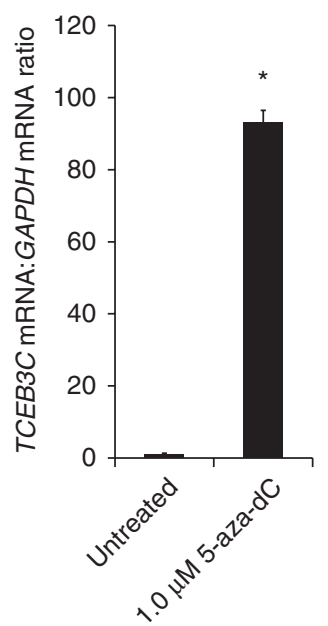

D
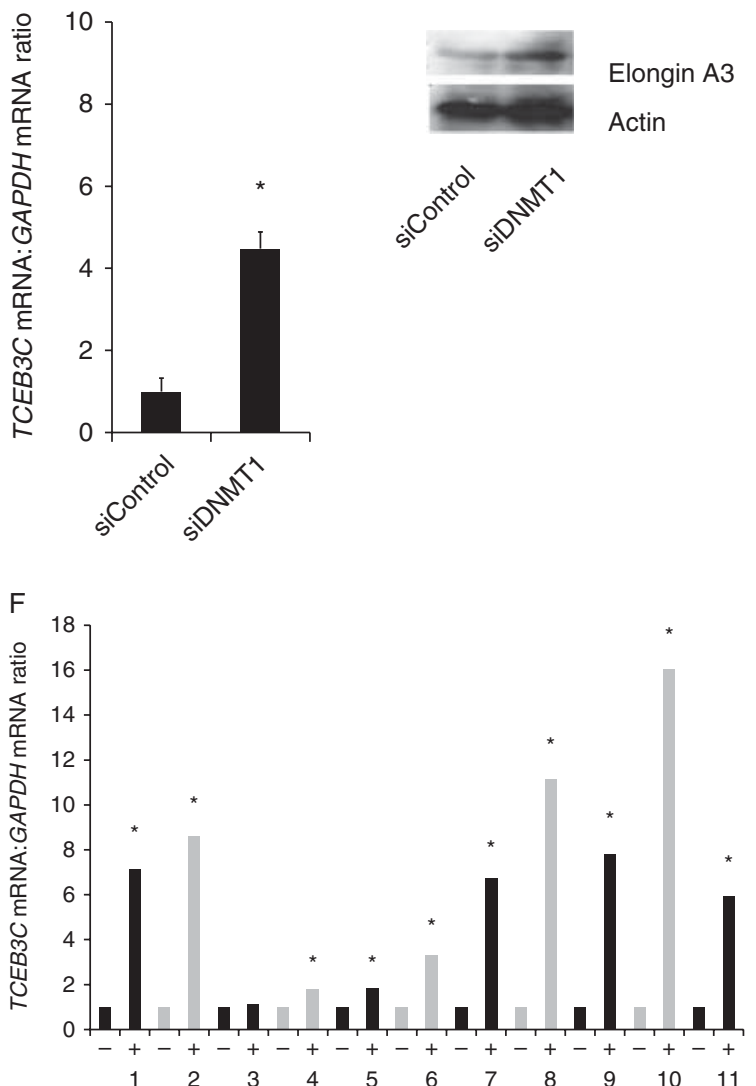

Figure 2

Effects on TCEB3C mRNA and protein (Elongin A3) expression after 5-aza-dC treatment and siRNA transfections. (A, B, C, D, and E) CNDT2.5 cells. (F) Primary SI-NET cell cultures $(n=11)$. (A) TCEB3C mRNA after 5 -aza-dC treatment. (B) Elongin A3 after 5-aza-dC treatment. (C) DNMT1 protein expression after siControl or siDNMT1 transfection. (D) TCEB3C mRNA after siControl or siDNMT1 transfection. (E) Elongin A3 after siControl or siDNMT1 transfection. (F) TCEB3C mRNA after $-/+5$-aza-dC treatment. ${ }^{*} P<0.05$.

CC 2014 Society for Endocrinology Printed in Great Britain
Next, CNDT2.5 cells were treated with DZNep, a global histone methyltransferase inhibitor. Also this treatment strongly induced TCEB3C mRNA expression (80-fold) and detectably increased Elongin A3 expression (Fig. 3A and B). Repressive histone methylations therefore also play a role in repression of TCEB3C in this cell type. We also analyzed the effects of the epigenetic drugs in HEK293T and sHPT-1 cells, both harboring one TCEB3C gene copy. Elongin A3 could readily be detected in sHPT-1 cells by western blotting and approximately ten times more TCEB3C mRNA was expressed in these cells compared with CNDT2.5 cells, and at least ten times more mRNA was expressed in the HEK293T cells (data not shown). 5-aza-dC failed to induce expression of TCEB3C in both cell lines. DZNep showed no effect in sHPT-1 cells and a small but significant effect in the HEK293T cells (Fig. 3C). Thus, epigenetic repression of TCEB3C seems to be tumor cell type-specific and likely involves both DNA and histone methylation.
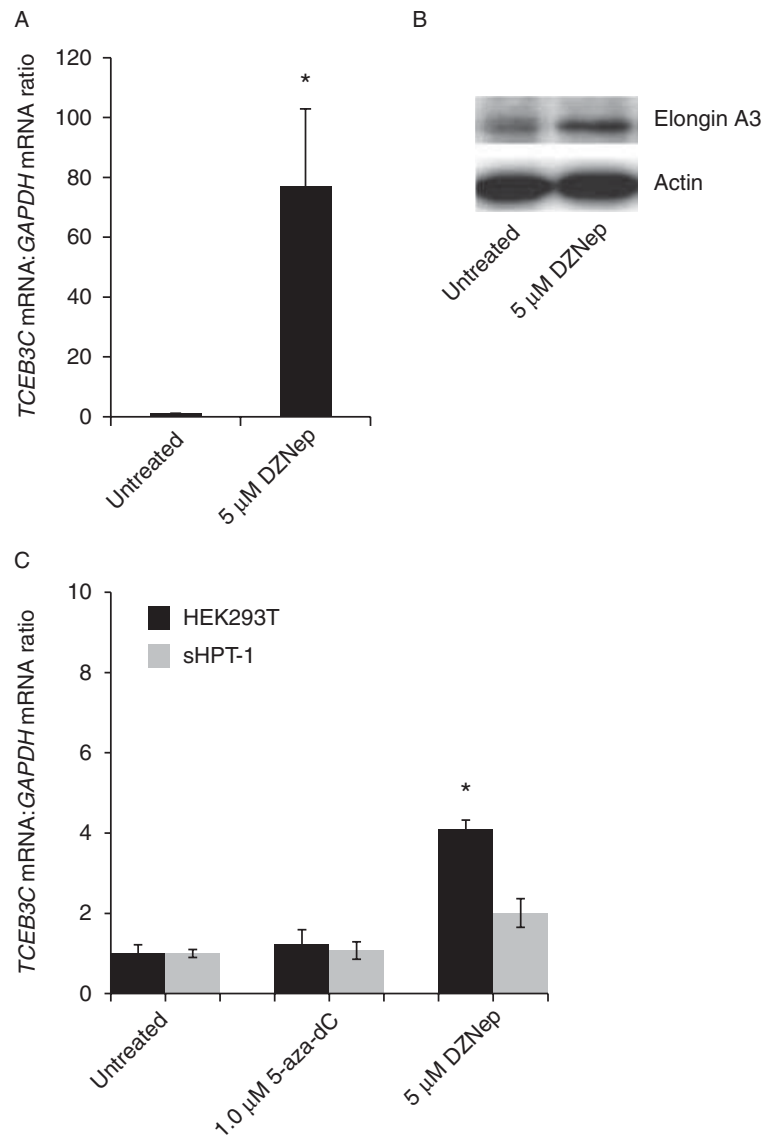

Figure 3

Effects on TCEB3C mRNA and protein (Elongin A3) expression after DZNep treatment in CNDT2.5 cells ( $A$ and $B$ ). Effects of 5-aza-dC and DZNep in HEK293T and sHPT-1 cells (C). * $P<0.05$.

Published by Bioscientifica Ltd. 


\section{The TCEB3C promoter region is CpG methylated}

The TCEB3C gene consists of one exon and is very CpG-rich with large CpG islands. The presence of CpG methylation in the promoter region was first established by bisulfite sequencing (data not shown). Quantitative pyrosequencing then revealed high level ( $90 \%)$ of $\mathrm{CpG}$ methylation in all 14 investigated SI-NETs (Fig. 4A). As expected, the treatment of CNDT2.5 cells with 5 -aza-dC or transfection of siDNMT1 caused a reduction in the mean methylation level, to 56 and $80 \%$ respectively (Fig. 4B). Thus, the expected relationship between induced TCEB3C expression and decreased promoter DNA methylation was observed in these cells. Somewhat unexpected, the TCEB3C promoter was found to be highly methylated (Fig. 4C) also in the TCEB3C-expressing cell lines, sHPT-1 (91\%) and HEK293T (89\%). Furthermore, high methylation (89\%) was also detected in normal kidney, displaying two gene copies and prominent expression of Elongin A3 (Fig. 4C). Therefore, the induction of TCEB3C by 5 -aza-dC in the SI-NET cell line probably involves demethylation of cell type-specific regulatory elements other than the limited promoter region analyzed in this study. It could also be due to indirect effects.

\section{A growth regulatory role of Elongin A3 in SI-NET cells}

To investigate whether TCEB3C could play a growth regulatory role, a colony formation assay was performed with transfection of a TCEB3C expression vector to the CNDT2.5 SI-NET cell line followed by G418 selection of TCEB3C-expressing cells. Overexpression of TCEB3C resulted in a significant reduced number $(50 \%)$ of cell colonies (Fig. 5A and B). No growth inhibitory effect was seen in parathyroid sHPT-1 cells (Fig. 5C and D) or HEK293T cells (Fig. 5E and F). These results support a tumor suppressor role of TCEB3C in SI-NET cells.

\section{Discussion}

Not much is known regarding Elongin A3 function, except that it can form a stable complex with Elongin $\mathrm{BC}$ and stimulate elongation by RNA polymerase II in vitro, just like Elongin A (Yamazaki et al. 2002). Elongins B (TCEB2) and $C$ (TCEB1) play an important role in tumor suppression by von Hippel-Lindau (VHL), where the VHL protein binds to the same Elongin BC binding sequence as Elongin A (TCEB3) and among other targets also binds to the $\alpha$ subunits of hypoxia-inducible factor and promote their ubiquitination and proteosomal
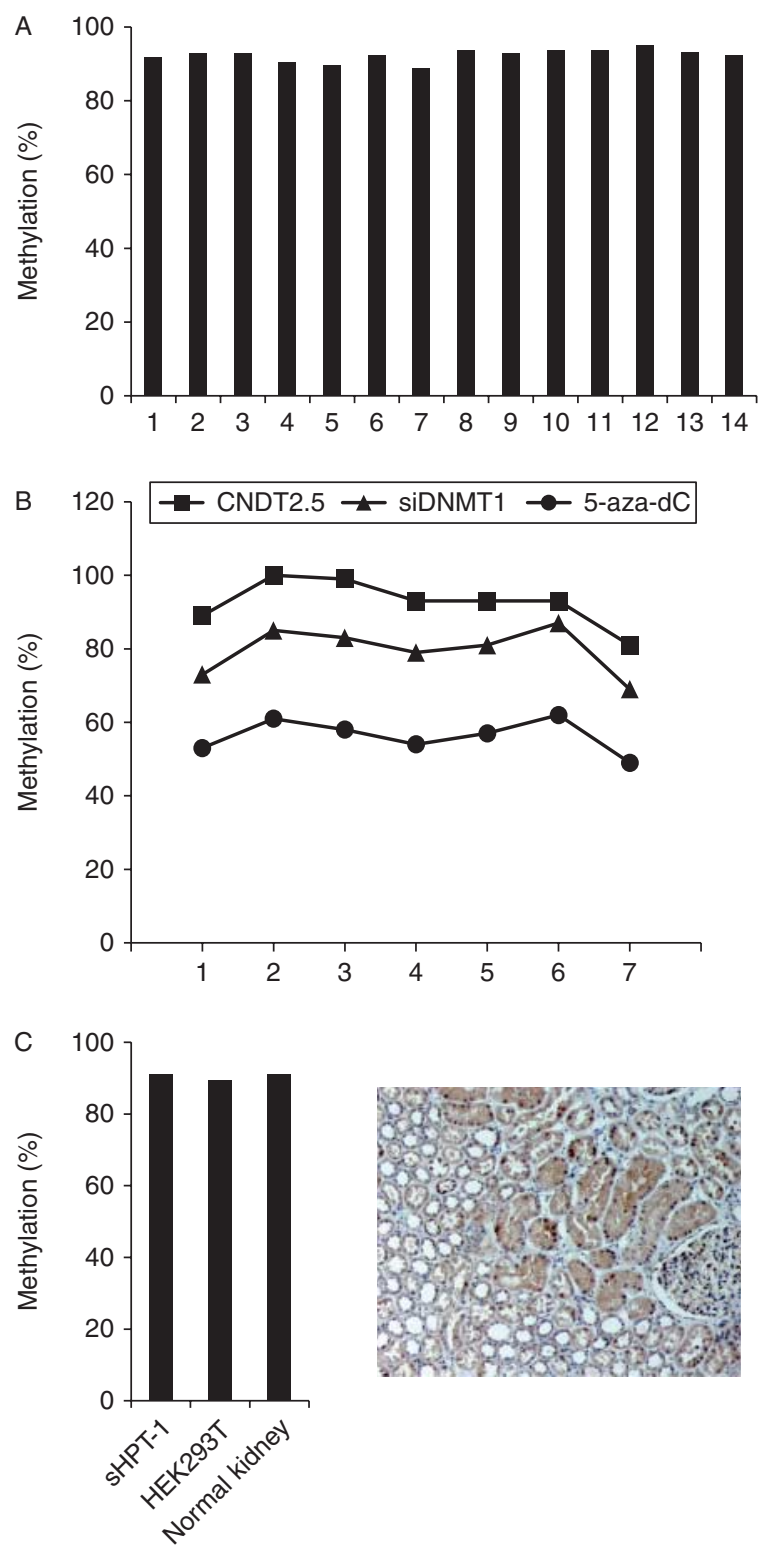

Figure 4

Quantitative bisulfite pyrosequencing analysis measuring methylation of seven $\mathrm{CpG}$ in the TCEB3C promoter region. (A) Mean methylation level in SI-NETs $(n=14)$. (B) Methylation level of individual CpGs in untreated, siDNMT1 transfected, and in 5-aza-dC treated CNDT2.5 cells. (C) Mean methylation level in SHPT-1, HEK293T, and normal kidney. Right panel, immunostaining of normal kidney with the anti-TCEB3C rabbit polyclonal antibody.

degradation. More than $70 \%$ of VHL familial and sporadic mutations affect the VHL Elongin C binding site (Conaway et al. 1998, Zhang \& Yang 2012). Elongin A on the other hand can mediate DNA damage-induced ubiquitination and degradation of the largest subunit of RNA polymerase II together with Elongin BC and the Cul5/Rbx2 module (Yasukawa et al. 2008).

Published by Bioscientifica Ltd. 
A

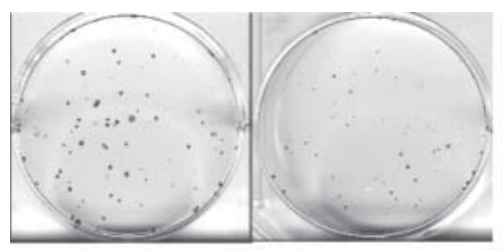

Empty vector TCEB3C

C

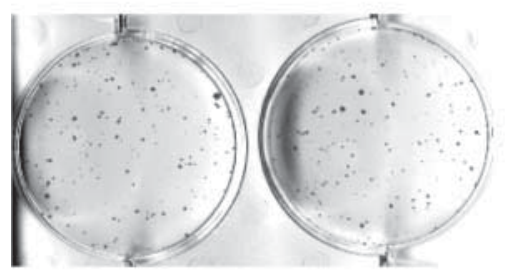

Empty vector

TCEB3C

E

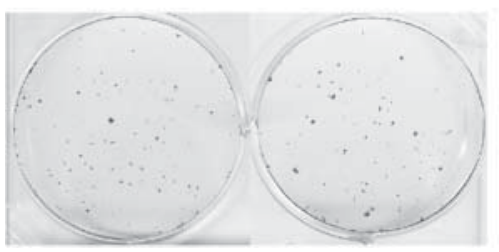

Empty vector

TCEB3C

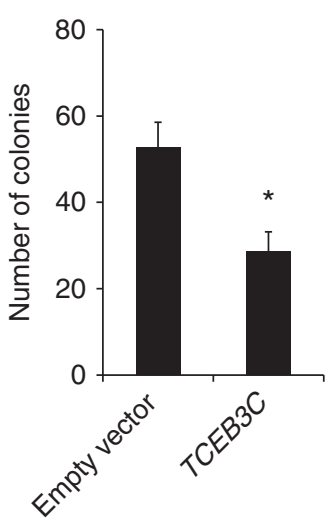

D

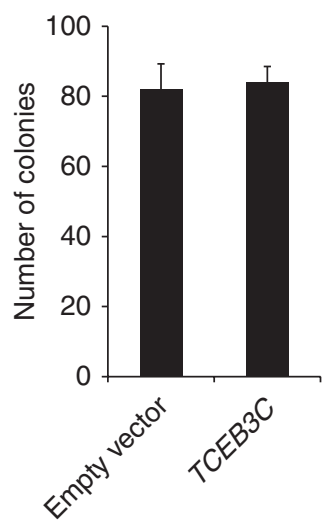

F

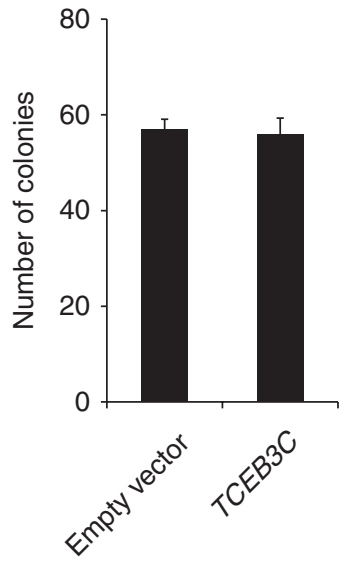

B
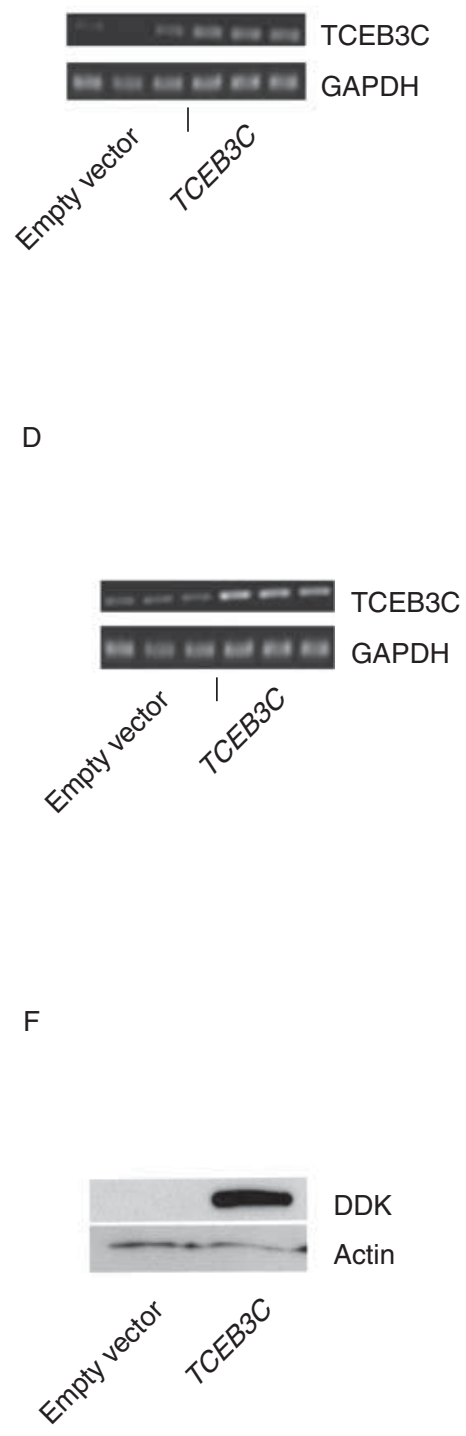

\section{Figure 5}

Colony formation assay in CNDT2.5 (A and B), sHPT-1 (C and D), and HEK293T (E and F). Cells were transfected with an expression vector for TCEB3C or empty vector and were selected by incubation with G418 for 8 days. ( $B$ and $D$ ) Successful transfection was monitored by expression of

Like Elongin A and VHL, Elongin A3 possesses the Elongin $\mathrm{C}$ binding sequence and can form a putative ubiquitylation complex with Elongin BC and Cul5/Rbx2 (Yamazaki et al. 2002). Interestingly, Elongin C (TCEB1)
TCEB3C by RT-PCR for CNDT2.5 and SHPT-1. (F) Successful transfection in HEK293T was observed by western blotting analysis with an antibody to the DDK epitope, fused to Elongin A3. * $P<0.05$.

has been shown to be overexpressed and to promote invasion of prostate cancer cells (Jalava et al. 2009).

A number of investigations have found frequent (43-100\%) aberrations on chromosome 18 in primary and

Published by Bioscientifica Ltd 
metastatic SI-NETs, using a variety of techniques, such as LOH, CGH, CGH-array, SNP analysis, and SNP-array (Kytola et al. 2001, Löllgen et al. 2001, Tonnies et al. 2001, Stancu et al. 2003, Wang et al. 2005, Kim do et al. 2008, Kulke et al. 2008, Andersson et al. 2009, Cunningham et al. 2011, Walsh et al. 2011). Perhaps the most conspicuous finding is the observation of frequent loss of one copy of the whole chromosome. Smaller deletions not necessarily overlapping have only been found in a few tumors (summarized in Cunningham et al. (2011)). Mutational analysis of candidate tumor suppressor genes have been performed for SMAD4, SMAD2, and 18 additional genes in the 18q21-18q22 region, without identifying any mutations (Löllgen et al. 2001, Kulke et al. 2008, Cunningham et al. 2011). Massively parallel exome sequencing of SI-NETs in one study did not reveal recurrently mutated genes (Banck et al. 2013), but recent analysis of a different tumor cohort identified a relatively low frequency of recurrent mutations ( $~ 9 \%)$, in the cyclindependent kinase inhibitor gene $C D K N 1 B$ on chromosome 12p13.1-p12 (Francis et al. 2013). Imprinted genes are of particular interest in cancer because only one mutational hit is required to fulfill the Knudson's two-hit hypothesis of tumor suppressor genes. The imprinted allele is normally inactivated by epigenetic mechanisms, in a way that could be tissue specific (Ferguson-Smith 2011, Uribe-Lewis et al. 2011). TCEB3C is currently the only known imprinted gene on chromosome 18 (http://www.geneimprint.com) and is located at 18q21.1. The data presented in this study strongly support a putative role of TCEB3C as tumor suppressor in SI-NETs. The majority of tumors had one TCEB3C gene copy (in 40/45, 89\%), showed prominently reduced expression of Elongin A3 (in 20/26, 77\%) and overexpression led to a decrease in clonogenic survival of SI-NET tumor cells and not of control cells. Epigenetic repression of TCEB3C expression was found to be SI-NET cell-specific and regulated by DNA and histone methylation. Gene induction after treatment with 5-aza-dC or DZNep could in principle also be due to indirect effects, although perhaps less likely here as both compounds strongly induced expression of TCEB3C. 5-aza-dC induced TCEB3C expression in the cultured primary SI-NET cells containing either one or two copies of the TCEB3C gene, supporting the possibility that the gene is imprinted in this cell type. Heterogenous Elongin A3 expression, including the lining of positive cells around negative insular cells, as was observed for 14 SI-NETs, may be understood by the reversible nature of epigenetic deregulation of gene expression.

Further studies on a putative role of TCEB3C (Elongin A3) as a tumor suppressor gene in SI-NET cells are warranted and it will be of interest to investigate a possible role of Elongin A3 in ubiquitination.

\section{Supplementary data}

This is linked to the online version of the paper at http://dx.doi.org/10.1530/ ERC-13-0419.

\section{Declaration of interest}

The authors declare that there is no conflict of interest that could be perceived as prejudicing the impartiality of the research reported.

\section{Funding}

This work was supported by grants from The Swedish Research Council, The Swedish Cancer Society, and Lions Fund for Cancer Research.

\section{Acknowledgements}

The authors are grateful to B Bondeson and P Lillhager for skilful technical assistance. The authors thank Dr Lee Ellis for making the CNDT2.5 cell line available to them

\section{References}

Andersson E, Sward C, Stenman G, Ahlman H \& Nilsson O 2009 Highresolution genomic profiling reveals gain of chromosome 14 as a predictor of poor outcome in ileal carcinoids. Endocrine-Related Cancer 16 953-966. (doi:10.1677/ERC-09-0052)

Banck M, Kanwar R, Kulkarni A, Boora G, Metge F, Kipp B, Zhang L, Thorland E, Minn K, Tentu R et al. 2013 The genomic landscape of small intestine neuroendocrine tumors. Journal of Clinical Investigation 123 2502-2508. (doi:10.1172/JCI67963)

Björklund P, Åkerström G \& Westin G 2007 Activated $\beta$-catenin in the novel human parathyroid tumor cell line sHPT-1. Biochemical and Biophysical Research Communications 352 532-536. (doi:10.1016/ j.bbrc.2006.11.056)

Bosman FT, Carneiro F, Hruban RH \& Theise ND 2010 WHO Classification of Tumours of the Digestive System. Geneva, Switzerland: WHO.

Conaway JW, Kamura T \& Conaway RC 1998 The Elongin BC complex and the von Hippel Lindau tumor suppressor protein. Biochimica et Biophysica Acta 1377 M49-M54.

Cunningham JL, Diaz de Stahl T, Sjöblom T, Westin G, Dumanski JP \& Janson ET 2011 Common pathogenetic mechanism involving human chromosome 18 in familial and sporadic ileal carcinoid tumors. Genes, Chromosomes \& Cancer 50 82-94. (doi:10.1002/gcc.20834)

Ellis LM, Samuel S \& Sceusi E 2010 Varying opinions on the authenticity of a human midgut carcinoid cell line - letter. Clinical Cancer Research 16 5365-5366. (doi:10.1158/1078-0432.CCR-10-2550)

Ferguson-Smith AC 2011 Genomic imprinting: the emergence of an epigenetic paradigm. Nature Reviews. Genetics 12 565-575. (doi:10.1038/nrg3032)

Francis JM, Kiezun A, Ramos AH, Serra S, Pedamallu CS, Qian ZR, Banck MS, Kanwar R, Kulkarni AA, Karpathakis A et al. 2013 Somatic mutation of CDKN1B in small intestine neuroendocrine tumors. Nature Genetics $\mathbf{4 5}$ 1483-1486. (doi:10.1038/ng.2821)

de Herder WW 2007 Biochemistry of neuroendocrine tumours. Best Practice \& Research. Clinical Endocrinology \& Metabolism 21 33-41. (doi:10.1016/ j.beem.2006.12.002) http://erc.endocrinology-journals.org DOI: 10.1530/ERC-13-0419
(C) 2014 Society for Endocrinology Printed in Great Britain
Published by Bioscientifica Ltd 
Jalava SE, Porkka KP, Rauhala HE, Isotalo J, Tammela TL \& Visakorpi T 2009 TCEB1 promotes invasion of prostate cancer cells. International Journal of Cancer 124 95-102. (doi:10.1002/ijc.23916)

Jones PA 2012 Functions of DNA methylation: islands, start sites, gene bodies and beyond. Nature Reviews. Genetics 13 484-492. (doi:10.1038/ nrg3230)

Kim do H, Nagano Y, Choi IS, White JA, Yao JC \& Rashid A 2008 Allelic alterations in well-differentiated neuroendocrine tumors (carcinoid tumors) identified by genome-wide single nucleotide polymorphism analysis and comparison with pancreatic endocrine tumors. Genes, Chromosomes \& Cancer 47 84-92. (doi:10.1002/gcc.20510)

Kulke MH, Freed E, Chiang DY, Philips J, Zahrieh D, Glickman JN \& Shivdasani RA 2008 High-resolution analysis of genetic alterations in small bowel carcinoid tumors reveals areas of recurrent amplification and loss. Genes, Chromosomes \& Cancer 47 591-603. (doi:10.1002/gcc.20561)

Kytola S, Hoog A, Nord B, Cedermark B, Frisk T, Larsson C \& Kjellman M 2001 Comparative genomic hybridization identifies loss of 18q22-qter as an early and specific event in tumorigenesis of midgut carcinoids. American Journal of Pathology 158 1803-1808. (doi:10.1016/S00029440(10)64136-3)

Li SS, Yu SL \& Singh S 2010 Epigenetic states and expression of imprinted genes in human embryonic stem cells. World Journal of Stem Cells 2 97-102. (doi:10.4252/wjsc.v2.i4.97)

Li SC, Martijn C, Cui T, Essaghir A, Luque RM, Demoulin JB, Castano JP, Öberg K \& Giandomenico V 2012 The somatostatin analogue octreotide inhibits growth of small intestine neuroendocrine tumour cells. PLoS ONE 7 e48411. (doi:10.1371/journal.pone.0048411)

Liu W, Ridefelt P, Åkerström G \& Hellman P 2001 Differentiation of human parathyroid cells in culture. Journal of Endocrinology 168 417-425. (doi:10.1677/joe.0.1680417)

Löllgen RM, Hessman O, Szabo E, Westin G \& Åkerström G 2001 Chromosome 18 deletions are common events in classical midgut carcinoid tumors. International Journal of Cancer 92 812-815. (doi:10.1002/ijc.1276)

Miranda TB, Cortez CC, Yoo CB, Liang G, Abe M, Kelly TK, Marquez VE \& Jones PA 2009 DZNep is a global histone methylation inhibitor that reactivates developmental gene not silenced by DNA methylation. Molecular Cancer Therapeutics 8 1579-1588. (doi:10.1158/1535-7163. MCT-09-0013)

Norlen O, Stalberg P, Öberg K, Eriksson J, Hedberg J, Hessman O, Janson ET, Hellman P \& Åkerström G 2012 Long-term results of surgery for small intestinal neuroendocrine tumors at a tertiary referral center. World Journal of Surgery 36 1419-1431. (doi:10.1007/s00268-011-1296-z)

Stålberg P, Hellman P \& Åkerström G 2009 Carcinoid: Presentation and Diagnosis, Surgical Management. Springer-Verlag London Limited: Springer Specialist Surgery Series.
Stancu M, Wu TT, Wallace C, Houlihan PS, Hamilton SR \& Rashid A 2003 Genetic alterations in goblet cell carcinoids of the vermiform appendix and comparison with gastrointestinal carcinoid tumors. Modern Pathology 16 1189-1198. (doi:10.1097/01.MP.0000097362.10330.B1)

Strichman-Almashanu LZ, Lee RS, Onyango PO, Perlman E, Flam F, Frieman MB \& Feinberg AP 2002 A genome-wide screen for normally methylated human CpG islands that can identify novel imprinted genes. Genome Research 12 543-554.

Tonnies H, Toliat MR, Ramel C, Pape UF, Neitzel H, Berger W \& Wiedenmann B 2001 Analysis of sporadic neuroendocrine tumours of the enteropancreatic system by comparative genomic hybridisation. Gut 48 536-541. (doi:10.1136/gut.48.4.536)

Uribe-Lewis S, Woodfine K, Stojic L \& Murrell A 2011 Molecular mechanisms of genomic imprinting and clinical implications for cancer. Expert Reviews in Molecular Medicine 13 e2. (doi:10.1017/ S1462399410001717)

Van Buren G II, Rashid A, Yang AD, Abdalla EK, Gray MJ, Liu W, Somcio R, Fan F, Camp ER, Yao JC et al. 2007 The development and characterization of a human midgut carcinoid cell line. Clinical Cancer Research 13 4704-4712. (doi:10.1158/1078-0432.CCR-06-2723)

Walsh KM, Choi M, Oberg K, Kulke MH, Yao JC, Wu C, Jurkiewicz M, Hsu LI, Hooshman SM, Hassan M et al. 2011 A pilot genome-wide association study shows genomic variant enriched in the non-tumor cells of patients with well-differentiated neuroendocrine tumor of the ileum. Endocrine-Related Cancer 18 171-180. (doi:10.1677/ ERC-10-0248)

Wang GG, Yao JC, Worah S, White JA, Luna R, Wu TT, Hamilton SR \& Rashid A 2005 Comparison of genetic alterations in neuroendocrine tumors: frequent loss of chromosome 18 in ileal carcinoid tumors. Modern Pathology 18 1079-1087. (doi:10.1038/modpathol.3800389)

Yamazaki K, Guo L, Sugahara K, Zhang C, Enzan H, Nakabeppu Y, Kitajima S $\&$ Aso T 2002 Identification and biochemical characterization of a novel transcription elongation factor, Elongin A3. Journal of Biological Chemistry 277 26444-26451. (doi:10.1074/jbc.M202859200)

Yao JC, Hassan M, Phan A, Dagohoy C, Leary C, Mares JE, Abdalla EK, Fleming JB, Vauthey JN, Rashid A et al. 2008 One hundred years after "carcinoid": epidemiology of and prognostic factors for neuroendocrine tumors in 35,825 cases in the United States. Journal of Clinical Oncology 26 3063-3072. (doi:10.1200/JCO.2007.15.4377)

Yasukawa T, Kamura T, Kitajima S, Conaway RC, Conaway JW \& Aso T 2008 Mammalian Elongin A complex mediates DNA-damage-induced ubiquitylation and degradation of Rpb1. EMBO Journal 27 3256-3266. (doi:10.1038/emboj.2008.249)

Zhang Q \& Yang H 2012 The roles of VHL-dependent ubiquitination in signaling and cancer. Frontiers in Oncology 2 35. (doi:10.3389/ fonc.2012.00035)

Received in final form 10 December 2013

Accepted 12 December 2013

Made available online as an Accepted Preprint

18 December 2013 http://erc.endocrinology-journals.org

DOI: 10.1530/ERC-13-0419
(C) 2014 Society for Endocrinology Printed in Great Britain
Published by Bioscientifica Ltd 